\title{
Investigation of Cost Effective and Efficient Solar Collector: A
} Review

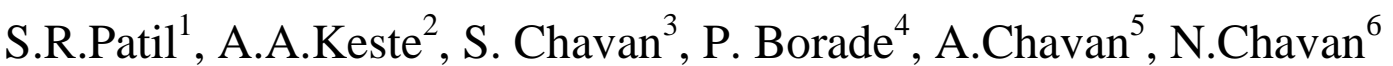 \\ ${ }^{1}$ Research scholar, MewarUniversity, Chittorgarh, Rajasthan, India \\ ${ }^{2}$ Department of Mechanical Engineering, M.E.S College of Engineering, Pune, S. P. Pune University,India. \\ ${ }^{3456}$ Department of Mechanical Engineering, Sinhgad Academy ofEngineeing, Pune, India
}

\begin{abstract}
Energy is a crucial input in the process of economic, social and industrial development .Besides the other three classical factors i.e. land, capital and labour, energy is of vital importance in the context of development. The energy demand is expected to triple before 2025. With the increasing per capita power consumption the depletion of conventional resources, an increase in the cost of power production and environmental pollution are emerging problems of concern. Seeking alternate resources and technologies will be solutions to these problems to a great extent. The conventional solar collectors are a costly affair; need space for installation and regular maintenance. These solar water heater are suitable where water at relatively high temperatures is required. Cheaper methods may be adopted where the hot water at relatively lowers temperatures is needed in buildings to meet the requirements for different purposes during the day. At present there are many industrial applications for hot water in the temperature range of $45^{\circ} \mathrm{C}$ to $65^{\circ} \mathrm{C}$. There are various conventional and non-conventional methods available to produce large quantity of hot water $\left(45^{\circ} \mathrm{C}\right.$ to $\left.65^{\circ} \mathrm{C}\right)$.Due to rapid rate of industrialization there has been accelerating demand for electrical power. At the same time average ambient temperatures are increasing in all parts of our country. To tackle such a hot ambient conditions prevailing in major parts of country an attempt can be made to use non-conventional cost effective simple method to produce hot water. With these facts in mind concrete solar collector will be developed, designed, fabricated and tested..This research aims at ascertaining the feasibility of utilizing building materials (concrete) for making solar collector and makes the collector more cost effective and efficient. Along with this metal fibres have been integrated with the cement to improve strength and conductivity of slab. This study suggests that the roof structure made of similar materials may be utilised as solar collectors to provide the hot water in the building at a relatively low cost This topic paves way for the possible integration of concrete collector with roof slab to provide human comfort and hot water requirement.

Keywords:- solar water heating, concrete, cost effective, metal fibres, integration.
\end{abstract}

\section{INTRODUCTION}

A large amount of metal like copper, aluminum etc.is used in conventional flat plate-collector systems. But studies on energy inputs required for the production of different materials indicates that metals need a large amount of fossil fuel energy for their production of different materials indicate that metals need a large amount of fossil fuel energy for their production.Furthermore, individual collector module is connected to form a large array to meet the required demand.Thus,the solar system forms a separate entity, which has its own individual cost and adds dead loads on a building structure .In the long run,it would seem desirable that solar collectors be made an integral part of building elements. Thus the separate solar investment would be partially merged into the building construction investment[2].

\subsection{Use of Concrete as absorber surface}

The absorptivity of concrete, if left unfinished is 0.65 , indicating that $65 \%$ of the solar radiation striking the surface of thermal storage wall is absorbed. Simply painting the concrete with flat black paint can increase the absorptivity to 0.96 . Concrete is essentially a mixture of two elements: aggregate and paste. The paste is made of Portland cement and water and it binds the aggregate consisting of crushed stone into a solid mass as it hardens due to chemical reaction between cement and water. In order to make design calculations applicable for all types of metal fibers and assuming random distribution of fibers a minimum value of 4.0 $\mathrm{W} / \mathrm{mk}$ is chosen for thermal conductivity of metal fiber reinforced concrete as suggested by Nayak [2]. 


\subsection{Literature review}

Relevant literature pertaining to study of performance of solar concrete collectors has been reviewed from different points. A number of studies have utilized concept of concrete collectors. A variety of experimental, analytical and computational research works has been carried out on enhancement of performance of collector.Turner et al. [1] studied concrete collectors for applications ranging from de-icing of roads and bridges to water heating required for various applications.S.P.Sukhatmeet al.[2] carried out experimental studies using PVC pipes embedded in wire mesh reinforced concrete. Consideration was given to tube-to-tube spacing as a parameter and an optimal pitch was established. Pressure drop through the tube network was also studied. The entire PVC pipe mesh was embedded inside the concrete slab.P.B.L.Chaurasia [3] carried out similar experiments as that of Sukhatme with the exception of using aluminum tubes instead of the PVC tubes used earlier. Parallel arrangement of pipe was constructed without glazing and 30\% of pipe was exposed to sunlight while $70 \%$ remained embedded in the concrete.Sokholof\&Reshef [4] studied thin concrete collectors with embedded tubes as well as transient analysis and concluded that these collectors could be used as building components providing a low cost energy collection means. Hajami et al. [5] have investigated performance of integrated concrete solar water heater. Absorber area of $5 \mathrm{~m}^{2}$ was constructed which worked on the principle of capillary exchanger embedded in concrete.

\section{EXPERIMENTAL SETUP}

The cement concrete collector in the form of thin slab have been fabricated and tested for water heating purpose. These reinforced cement concrete slabs have been made from common building materials like cement, sand and coarse aggregate. Approximately $25 \mathrm{~kg}$ cement, $100 \mathrm{~kg}$ sand was used to construct the slab. This mixture is poured into the wooden box at a height of $2 \mathrm{~cm}$ from the bottom. Mild Steel scrap which is approximately $15 \mathrm{~kg}$ is used in the fabrication of the slab which gives structural strength to the slab. The thermal conductivity of the slab also increases due to M.S scrap. Wire mesh is embedded at a height of $1.46 \mathrm{~cm}$ from bottom which provides reinforcement for the concrete slab.

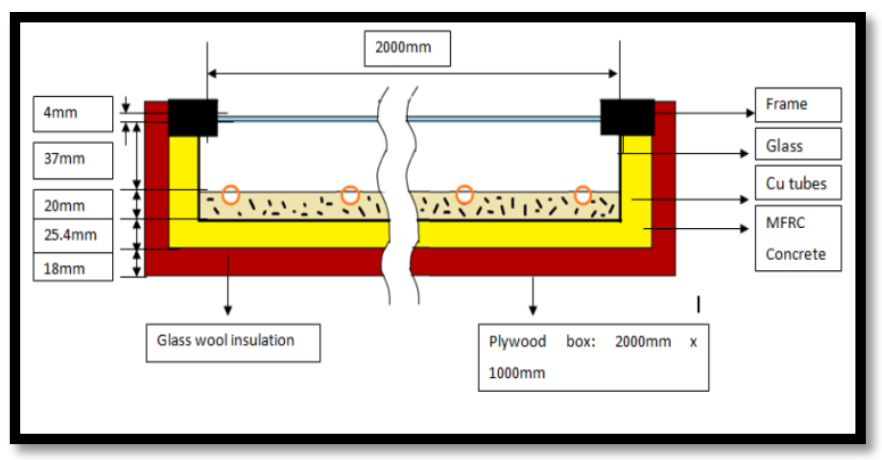

Fig.1 Cross section of concrete collector assembly

Fig. 1 shows the structural configuration the concrete slab. The dimensions of the slab are $2 \mathrm{~m} \mathrm{X} 1 \mathrm{~m}$ with an absorbing surface of approx. $2 \mathrm{~m}^{2}$.The thickness of the slab is $2 \mathrm{~cm}$. The copper tubes were embedded on the top surface. The arrangement of the copper tubes was made into serpentine flow arrangement. The copper tubes arranged in such a manner that $70 \%$ of its portion, along its length, remains inside the concrete slab while $30 \%$ remains exposed directly to the sunlight as suggested by Chaurasia[3]. The tube spacing was kept $80 \mathrm{~mm}$. This entire setup was placed in a wooden cabinet having inner size of the mould as $2 \mathrm{~m} \times 1 \mathrm{~m} X 0.1 \mathrm{~m}$.A $18 \mathrm{~mm}$ waterproof plywood was used to make the base and sides of the wooden cabinet. With reference to the copper grid size, two rectangular cuts are made at the side flank to have free access to inlet and outlet pipes. A $3 \mathrm{~mm}$ thick toughened glass was placed on the top of the wooden cabinet and fixed to it by means of proper gasket which also acts as an insulating tape [3]. A 100 liters capacity storage tank is connected to the collector by means of hose pipe. The collector is painted with blackboard paint to increase the absorptivity.FromJ.K.Nayak [2] , a comparison of the performance of collectors having pitches 15,10 , and $8 \mathrm{~cm}$ and parallelflow, it is seen that the reduction of pitch from 15 to $10 \mathrm{~cm}$ increases the efficiency appreciably. But if the pitch is further reduced to $6 \mathrm{~cm}$, the increase in the efficiency is not that significant. This behavior is observed in the case of both flow rates $(1.2$ and $0.6 \mathrm{lpm})$.Under similar conditions, the daily efficiency ofa concrete collector at a flow rate of $1.2 \mathrm{lpm}$ ishigher than that obtained at a flow rate of $0.61 \mathrm{pm}$. The difference is appreciable for inlet temperaturesclose to the ambient. The performance of the collector with a serpentine passage and $8 \mathrm{~cm}$ pitch is similar to that ofthe collectors having parallel flow and pitches of 6 and $10 \mathrm{~cm}$. As expected, the performance of the conventionalcollector is always better than the concretecollectors. 


\section{EXPERIMENTAL PROCEDURE}

Before starting the experimentglass covers are cleaned. The pyranometer is properly mounted and leveled in the collector plane. Theambient temperature and the solar radiation are recorded every $20 \mathrm{~min}$. The required flow rate is measured with the help of the rotameter. The $\mathrm{K}$ type thermocouplesare used to measure the desiredwater temperature. In the early morning hours, the incident solar radiation is not enough to bring the collectors to the operating condition. Therefore, the circulating water loses its heat to the collectors, giving a negative temperature rise. As the collectors gain energy and approach operating conditions, the tank heaters are put off one by one. Once the collectors start giving useful energy (positive temperature rise), the following data are recorded every $20 \mathrm{~min}$ : inlet water temperature (Tfi), outlet water temperature (Tfo), temperature rise through the collector $(\delta \mathrm{Tf})$, ambient temperature (To), solar flux incident on the collector plane (It), and volume flow rate $(\mathrm{Q})$ as suggested in Nayak[2]

\section{APPLICATIONS OF SOLARCONCRETE COLLECTORS}

If the roof of a concrete structure is blackened, more hot water will be taken.If the cold water from the overhead tank of the house is drawn through the network of the copper pipes embedded in the cement concrete structure it can easily supply the hot water ata moderate temperature $\left(36^{\circ} \mathrm{C}\right.$ to $\left.58^{\circ} \mathrm{C}\right)$ for meeting the various domestic requirements during theday, e.g. hot water in the bathroom, in the kitchen for utensil washing and cloth washing etc.About $25-40$ litres of hot water above the human body's temperature (i.e. above $36^{\circ} \mathrm{C}$ ) can bedrawn daily from one square meter area of roof structure after slight modifications in the regionswhere the horizontal solar insolation exceeds $4 \mathrm{kWh} / \mathrm{m}^{2}$.[9]The concept of the cement concrete solarwater heating system in the building is shown in Fig. 2For this purpose, reinforced cementconcrete slabs (R.C.C. slabs) can be used or the roof can be modified. The inbuilt cement concretesolar roof system for solar water heating can also be made during the construction of the house.This solar roof can also be employed as a pre-heater to any water heating system. This passivecement concrete solar water heating system can also be used in the summer season for supplyingthe hot water at relatively higher temperature which may be used according to the requirements of the buildings[7].

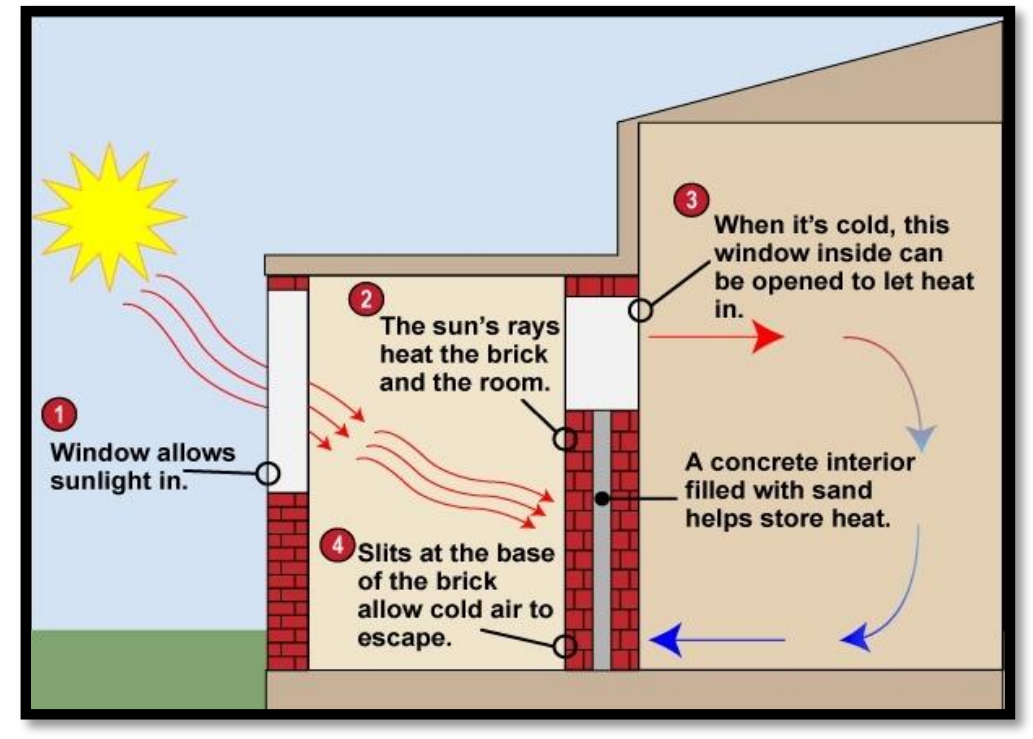

Fig.2. A concept of the cement concrete solar water heating system for passive solar water heating in buildings[3]

\section{FUTURE WORK}

The future work consists of utilizing heat transfer augmentation techniques in order to enhance the heat transfer rates between the concrete slabs and the water passing through the tubes.

\section{VI. . CONCLUSION}

Hot water at moderate temperature (upto $54^{\circ} \mathrm{C}$ ) can be obtained in buildings during thedaytime in winter by using reinforced cement concrete slabs or by slightly modifying the roofstructure and laying down a network of copper pipes over it which can offer a low cost passivesolar water heating system in the building itself. Inbuilt cement concrete solar water heatingsystem (i.e. integrated cement concrete system with roof) can 
also be made during the constructionof the building. This passive solar water heating technique is easy to fabricate and the mason orskilled person can do this type of job after a little training for it. Solar collector with dimple surface can be used for the further enhancement in heat transfer rate.

\section{References}

[1] Turner R.H,Concrete Slabs as winter solar collectors,ASME solar energy conference,pp 9-13

[2] Bopshetty S.V \&Nayak J.K, Performance Analysis of Solar Concrete Collector, EnergyConverse. Manage.,33(11),1007-1016

[3] ChaurasiaP.B.L,Solar water heaters based on concrete collectors,Energy,33(11),1007-1016

[4] Sokholof M. \&Reshef M., Performance Simulation of Solar Collectors made of concrete with embedded Conduit Lattice, Solar Energy,48(6),403-417

[5] Hazami M., Performance of Solar storage Collector, Desalination 183,167-172

[6] D Antoni M, Saro O Massive solar-Thermal collectors-A critical literature review Renewable and Sustainable Energy Reviews 16 (2012)

[7] Regsitsarachitti Thermal performance analysis and economic evaluation of roof integrated solar concrete collector Energy and buildings 43 (2011)

[8] B.A.Jubran, M.A.Al-saad, N.A.AbuFaris Computational evaluation of solar heating systems using concrete collectors Energy conversion and management. Volume 35, issue 12, Dec.1994

[9] Ashley Burnett Abbott (2004) "Analysis of thermal energy collection from Precast Concrete Roof Assemblies “. 